\title{
Ovarian autoimmunity in relation to egg production in laying hens
}

\author{
A. Barua ${ }^{1}$ and Y. Yoshimura ${ }^{2 *}$ \\ ${ }^{1}$ Graduate School for International Development and Cooperation and ${ }^{2}$ Faculty of Applied \\ Biological Science, Hiroshima University, Highashi-Hiroshima 739-8528, Japan
}

The aim of this study was to determine whether anti-ovarian autoantibodies appear in the circulation of laying hens and whether the concentrations of these antibodies change with respect to ageing and egg laying rate. Autoantibodies to ovarian tissues in the circulation of aged (aged approximately 670 days) White Leghorn hens with low $(<50 \%)$ and high $(>90 \%)$ egg laying rates were examined by ELISA and western blotting. Young laying hens (aged 185 days) with $>95 \%$ egg production were used as controls. The results of the ELISA indicated that IgG, which bound to the ovary and small white follicles, was present in the circulation of old laying hens. More hens that laid few eggs had circulatory autoantibodies to the ovary and small white follicles, as determined by the cut-off value in ELISA

\section{Introduction}

In hens, egg production decreases with the increase in follicular atresia that occurs during ageing (Bahr and Palmer, 1989). Waddington et al. (1985) reported that atresia of small follicles occurred at a higher incidence in old hens than young hens. Endocrinological studies have demonstrated that lack of adequate gonadotrophin support may be one of the major factors for the increased incidence of atresia with age in birds (Bahr and Palmer, 1989) and mammals (Richards, 1980). Johnson (1996) reported that follicular atresia in hens was mediated via a specific type of programmed cell death - apoptosis. This author also proposed that humoral factors and intracellular mechanisms might promote follicular atresia in pre-hierarchical follicles.

However, ovarian disorders in mammalian species also occur as a result of ovarian autoimmunity (Coulam, 1982; Kim et al., 1995). Irvine et al. (1968) reported that circulating humoral autoantibodies in women are a contributory factor to follicular death. Autoimmunity is a condition in which an immune response is directed against self tissues or components and may develop pathological consequences leading to disease (Benjamini and Leskowitz, 1991). In ovarian autoimmunity, immune responses occur

*Correspondence

Email: yyosimu@hiroshima-u.ac.jp (mean absorbance +2 SD of young laying hens), than did hens that laid greater numbers of eggs, and the concentration of $\operatorname{lgG}$ was significantly higher in the hens that laid few eggs. In contrast, when the muscle proteins were used as antigens there were no significant differences in the absorbance values among low and high laying frequency old hens or young hens. Western blotting revealed many bands of immunoprecipitates formed by ovarian antigens and antibodies in the serum of old hens, indicating the presence of many binding sites for circulatory IgG in ovarian tissues. These results indicate that antibodies to ovarian tissues appear in the circulation of laying hens during ageing, and that the concentration of these autoantibodies is related inversely to the rate of egg laying by hens.

against self ovarian tissues, resulting in ovarian disorders and follicular depletion (Coulam and Stern, 1991). Oocytes of the developing follicles, the zona pellucida, theca and granulosa cells are antigenic ovarian structures in mammalian ovaries (Cameron et al., 1988; LaBarbera et al., 1988; Monacayo and Monacayo, 1992). Vallotton and Forbes (1966) reported that antibodies against the ooplasm were present in the circulation of women with ovulation failure. Circulatory autoantibodies to gonadotrophin receptors may block gonadotrophin action, resulting in follicular atresia and ovarian dysfunction in mammals (Ruehsen et al., 1972; Austin et al., 1979; Chiauzzi et al., 1982; Kim et al., 1995).

Coulam and Stern (1991) proposed that abnormal expression of major histocompatibility complex class II (MHC II) antigens on the ovarian tissues and decreases in ovarian immunity might be the primary factors for induction of ovarian autoimmunity in mammals. In contrast, there is no information about whether ovarian autoimmunity occurs in hens. If autoantibodies appear in hens they may enhance atresia and, thus, reduce egg production. MHC II expressing cells, T cell subsets and immunoglobulin-containing cells are present in hen ovaries and their populations decrease during ageing of hens (Barua et al., 1998a,b; Barua and Yoshimura, 1999a,b). Therefore, it is possible that decreases and abnormalities in ovarian immunity may lead to induction of ovarian autoimmunity in aged hens, as has been proposed for mammals. The aim of the present study was to determine 
whether anti-ovarian antibodies appear in the circulation of laying hens and whether the concentrations of these antibodies change with respect to ageing and egg laying rate.

\section{Materials and Methods}

\section{Birds}

Young White Leghorn laying hens (aged 185 days with $>95 \%$ egg production; $n=10$ ) and old laying hens (aged approximately 670 days) were kept in individual cages under a light regimen of $14 \mathrm{~h}$ light: $10 \mathrm{~h}$ dark with food and water available ad libitum. The egg laying rates of the young hens were monitored approximately 15 days before the experiment. The laying patterns of old hens (experimental birds) were monitored for 2 months and the hens were then divided into two groups: hens with $<50 \%$ egg production (low laying frequency old hens; $n=10$ ) and hens with $>90 \%$ egg production (high laying frequency old hens; $n=10$ ). Serum samples were obtained from all birds and kept at $-20^{\circ} \mathrm{C}$ until used. Serum samples from young laying hens were used as control serum in ELISA.

\section{Preparation of antigens}

Ovarian tissues, small white follicles (3-4 mm in diameter) and skeletal muscle were collected from normally laying hens (aged approximately 210 days) of the experimental group and used as the antigens for ELISA and western blotting. The samples were homogenized with homogenization buffer (1\% (v/v) NP-40; $0.1 \% \quad(\mathrm{w} / \mathrm{v})$ sodium deoxycholate; 1\% (v/v) PMSF, $150 \mathrm{~mol} \mathrm{NaCl}$ ${ }^{-1}$ Tris-HCl; $\mathrm{pH}$ 7.5) using a Polytron homogenizer (PT 1200; Kinematica AG, Switzerland) on ice. Homogenized tissue samples were centrifuged for $15 \mathrm{~min}$ at $6200 \mathrm{~g}$ (MRX-150; Tomy Seiko Co, Tokyo) and the supernatants were collected. The protein concentrations in each sample were determined using protein assay reagent (Bio-Rad, Hercules, CA) according to the manufacturer's instructions (Bradford, 1976). Samples were kept frozen $\left(-80^{\circ} \mathrm{C}\right)$ until used as antigens in ELISA and western blotting.

\section{ELISA}

The presence of circulatory autoantibodies was examined by ELISA as described by Wheatcroft et al. (1994), with minor modifications. The wells of microtitre plates were coated with antigens by incubating with $100 \mu \mathrm{l}$ isolated ovarian, small white follicle or muscle protein samples (protein concentration was adjusted to $1 \mathrm{mg} \mathrm{ml}^{-1}$ with PBS) for $2 \mathrm{~h}$ at room temperature. After antigen coating, excess antigen solution was removed and non-specific sites were blocked with $1 \%(\mathrm{w} / \mathrm{v})$ casein milk in PBS at $4^{\circ} \mathrm{C}$ overnight. Wells were incubated with the serum $1: 10$ dilution in $1 \%(\mathrm{w} / \mathrm{v})$ BSA-PBS) of experimental birds for $2 \mathrm{~h}$ at room temperature. After washing with PBS containing $0.05 \%(\mathrm{v} / \mathrm{v})$ Tween-20 $(3 \times 5 \mathrm{~min}$ washes $)$, the wells were incubated with alkaline phosphatase conjugated rabbit anti-chicken IgG (Sigma, St Louis, MO) at a dilution of $1: 30000$ in $1 \%(\mathrm{w} / \mathrm{v})$ BSA-PBS at $37^{\circ} \mathrm{C}$ for $2 \mathrm{~h}$. Immunoreactions were developed using a p-nitrophenylphosphate substrate solution kit (KPL, Gaithersburg, MD). The plates were read in a microplate reader (Model 550 , Bio-Rad) at $405 \mathrm{~nm}$. All samples were assayed in duplicate within the same plate. A background absorbance value was obtained from the control well with the omission of serum. This measurement provided background values that could be subtracted from the absorbance values of experimental samples. After subtraction, the mean of two absorbance values for each sample was calculated and plotted in a dot diagram. Serum of young laying hens $(n=10)$ was used as control serum and the mean absorbance $+2 \mathrm{SD}$ of the control samples was used as a cut-off value between positive and negative for autoantibodies as described by Luborsky et al. (1990) and Wheatcroft et al. (1994). The absorbance values greater than the cut-off value were considered as positive for autoantibodies. The chi-squared test was used for statistical analysis of the frequency of birds with autoimmune serum. The level of significance was $P<0.01$.

\section{Western blotting}

Ovarian or small white follicle antigen samples $(1 \mathrm{mg}$ $\mathrm{ml}^{-1}$ ) were separated by electrophoresis on discontinuous SDS-polyacrylamide gels (4\% upper gel and 7.5\% lower gel) as described by Laemmli (1970). After electrophoresis the separated proteins in the lower gel were transferred electrophoretically onto nitrocellulose membrane (Hybond-C; Amersham International plc, Amersham) using a semi-dry blotting system with transfer buffer $(0.025 \mathrm{~mol}$ Tris-glycine $\mathrm{I}^{-1}(\mathrm{pH} 8.3)$ and $20 \%(\mathrm{v} / \mathrm{v})$ methanol). The membrane was washed with western buffer $(0.15 \mathrm{~mol}$ $\mathrm{NaCl}, 0.5 \%(\mathrm{v} / \mathrm{v})$ Tween-20 and $0.05 \%(\mathrm{w} / \mathrm{v})$ BSA in 0.02 mol Tris- $\left.-\mathrm{HCl} \mathrm{I}^{-1} ; \mathrm{pH} 7.4\right)$ for $30 \mathrm{~min}(3 \times 10 \mathrm{~min}$ washes). The membrane was blocked for $1 \mathrm{~h}$ at room temperature with $1 \%(\mathrm{w} / \mathrm{v})$ casein milk in PBS. After blocking, the membrane was cut into antigen-bearing strips. Each strip was incubated with a serum sample (diluted in PBS at a concentration of 1:100 for $2 \mathrm{~h}$ at room temperature) from a low or high laying frequency old hen. After washing with western buffer for $30 \mathrm{~min}$ ( $3 \times 10 \mathrm{~min}$ washes), the membrane strips were incubated with alkaline phosphataseconjugated rabbit anti-chicken IgG (Sigma) that had been diluted to 1:5000 in western buffer at room temperature for $2 \mathrm{~h}$. After washing with western buffer $(3 \times 10 \mathrm{~min}$ washes), the immunoprecipitates on the strips were visualized using a mixture of $3 \mathrm{mg}$ nitroblue tetrazolium and $3 \mathrm{mg}$ 5-bromo-4-chloro-3 indonyl phosphate in $10 \mathrm{ml}$ substrate buffer $(0.1$ mol Tris- $\mathrm{HCl} \mathrm{I-1}, \mathrm{pH} 9.6$, containing $1 \mathrm{mg} \mathrm{MgCl} \cdot 6 \mathrm{H}_{2} \mathrm{O}$ ). A background control strip, for which the incubation with serum sample was not performed, was included in each assay to identify the background band signals and endogenous $\lg \mathrm{G}$ originating from the antigen samples of ovary and small white follicles. The number of immunopositive protein bands on the strips was analysed 


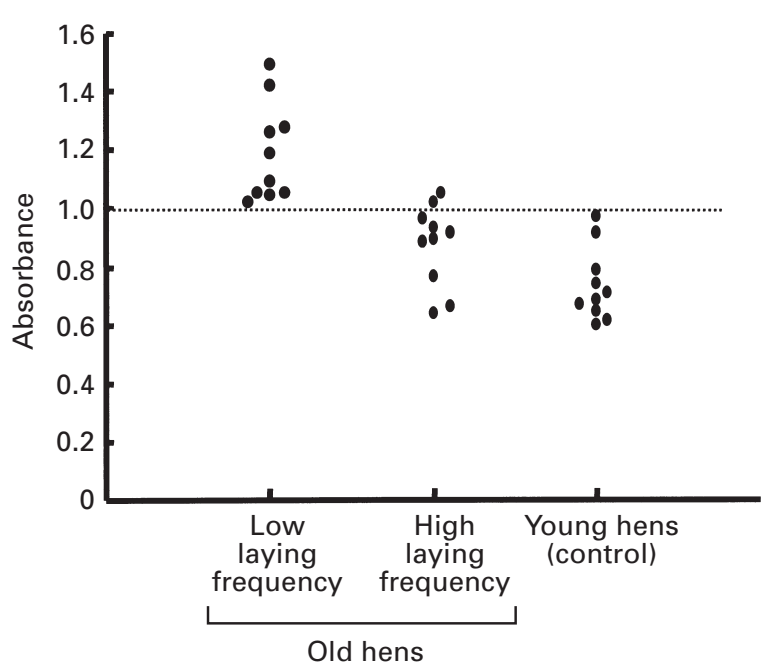

Fig. 1. ELISA dot plot diagram for anti-ovarian antibodies in hen serum samples. Binding of $\lg G$ to proteins isolated from the ovaries of hens was examined in the serum of low laying frequency old hens (aged approximately 670 days with $<50 \%$ egg production), high laying frequency old hens (aged approximately 670 days with $>90 \%$ egg production) and young hens (aged 185 days with $>95 \%$ egg production) ( $n=10$ birds in each group). The dotted line shows the cut-off value, which is the mean absorbance $+2 \mathrm{SD}$ of control (young laying hen serum).

by a computer assisted software program (Gel-Pro Analyzer; Media Cybernetics, The Image Experts, ML).

\section{Results}

\section{ELISA for anti-ovarian and anti-small white follicle antibodies}

The ELISA absorbance of serum from experimental (low or high laying frequency old hens) and control (young laying hens) birds against the ovary, small white follicle and skeletal muscle antigens are shown (Figs 1, 2 and 3, respectively). All the absorbance values of serum from low laying frequency old hens against the ovary and small white follicle antigens were above the cut-off value (mean absorbance +2 SD of control). Only two of ten serum samples from high laying frequency old hens had an absorbance value greater than the cut-off line in the analysis of both ovary and small white follicle antigens. In the young laying hen group none of the serum samples had an absorbance value greater than the cut-off line against the ovary and the small white follicle antigens. The frequency of birds with absorbance values above the cut-off line for both the anti-ovary and anti-small white follicle antibodies was significantly higher for low laying frequency old hens than high laying frequency old hens $(P<0.01)$. The correlation between the individual absorbance values and egg laying rates was not significant within the low laying frequency old hen group. However, the mean absorbance values in low laying frequency old hens (ovary:

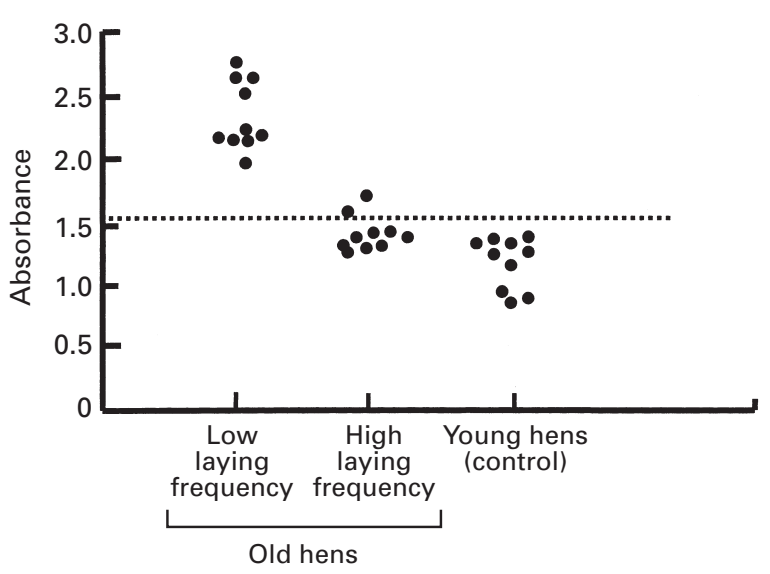

Fig. 2. ELISA dot plot diagram for anti-small white follicle antibodies in hen serum samples. Binding to proteins isolated from small white follicles was analysed in the serum of low laying frequency old hens (aged approximately 670 days with $<50 \%$ egg production), high laying frequency old hens (aged approximately 670 days with $>90 \%$ egg production) and young hens (aged 185 days with $>95 \%$ egg production) ( $n=10$ birds in each group). The dotted line shows the cut-off value, which is the mean absorbance +2 SD of control (young laying hen serum).

$1.19 \pm 0.05$; small white follicle: $73 \pm 0.11$ ) were significantly higher than in either high laying frequency old hens (ovary: $0.87 \pm 0.04$; small white follicle: $21.43 \pm 0.03$ ) or control hens (ovary: $0.73 \pm 0.04$; small white follicle: $1.16 \pm 0.06)$ in the analysis of both the ovary and small white follicles $(n=10 ; P<0.01)$. In contrast, no absorbance value was found to be above the cut-off value in all serum samples from both experimental and control birds for muscle antigens.

\section{Western blotting for anti-ovarian and anti-small white follicle antibodies}

The results of immunoblotting for the serum from low laying frequency or high laying frequency old hens against the ovary and small white follicles are shown (Figs 4 and 5). In both tissues, many bands of various sizes were observed in the serum of both low and high laying frequency old hens. Although one of four birds in the high laying frequency old hen group showed some dense bands in the ovarian antigen, the number of bands was greater in samples from low laying frequency old hens than in samples from high laying frequency old hens.

\section{Discussion}

This is the first report of the appearance of ovarian autoimmunity in laying hens. The significant findings of this experiment are: (i) IgG, which binds to the ovarian tissues, was present in the circulation of old laying hens; (ii) the frequency of birds with higher concentrations of this $\lg \mathrm{G}$ was significantly greater in the low laying frequency old hen group than in the high laying frequency old hen 


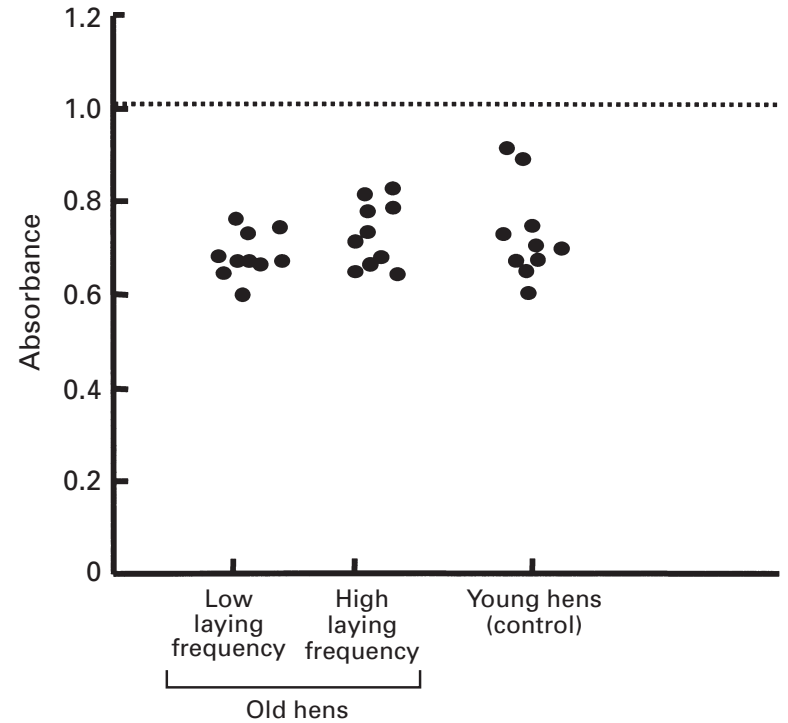

Fig. 3. ELISA dot plot diagram for anti-muscle antibodies in hen serum samples. Binding of IgG to skeletal muscle proteins was examined in the serum of low laying frequency old hens (aged approximately 670 days with $<50 \%$ egg production), high laying frequency old hens (aged approximately 670 days with $>90 \%$ egg production) and young hens (aged 185 days with $>95 \%$ egg production) ( $n=10$ birds in each group). The dotted line shows the cut-off value, which is the mean absorbance $+2 \mathrm{sD}$ of control (young laying hen serum).

group; and (iii) the serum $\lg G$ from old hens bound to molecules of various sizes in ovarian and small white follicle samples.

In ELISA analysis, the mean absorbance $+2 \mathrm{SD}$ of control has been proposed as the cut-off value between negative and positive sera for detection of anti-ovarian antibodies in mammals (Luborsky et al., 1990; Wheatcroft et al., 1994; Fenichel et al., 1997). These authors proposed that absorbance values greater than the cut-off value are indicative of the presence of autoantibodies. In the present study, all of the serum samples from low laying frequency old hens had absorbance values greater than the cut-off value, which is indicative of the presence of autoantibodies to the ovary and small white follicles. In western blotting of ovarian and small white follicle peptides, many bands were observed in all the serum samples from both low and high laying frequency old hens. This finding indicates that there are antigenic molecules of various sizes for the circulating autoantibodies in these tissues. Similar findings were also reported by Wheatcroft et al. (1994), who observed many immunoreactive bands of various sizes using serum from women with autoimmune disease against ovarian antigens. In contrast, binding of the serum of old laying hens to skeletal muscle peptides was not observed. Therefore, it is likely that autoimmunity in low laying frequency old hens occurred against tissue-specific proteins; the ovary is a tissue that contains such proteins.

The frequency of hens with ovarian autoantibodies

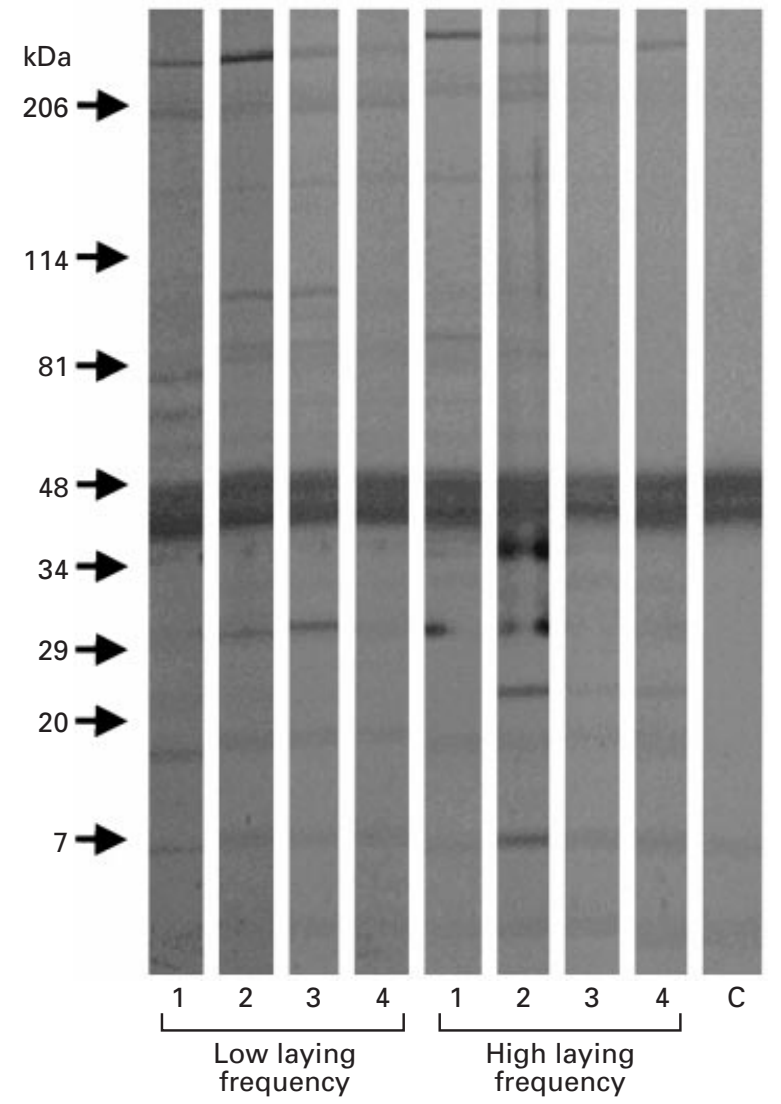

Fig. 4. Western blotting for serum from old laying hens against ovarian antigens. Low laying frequency: hens aged approximately 670 days with $<50 \%$ egg production (individual hens $1-4$ ). High laying frequency: hens aged approximately 670 days with $>90 \%$ egg production (individual hens 1-4). C: background control in which serum was omitted. Values in the left margin indicate the molecular size of protein bands. Dense bands of approximately 40-48 kDa show endogenous IgG that was contained in the ovarian tissue as they appear in lane C.

(above the cut-off value) was significantly greater in low laying frequency old hens than in high laying frequency old hens. Although the mean amount of autoantibody in older hens was not determined in the present study, the absorbance values showing the concentration of antibodies to ovarian tissues were significantly greater in the serum of low laying frequency old hens than in high laying frequency old hens. Therefore, the current findings indicate that there may be a correlation between decreased egg production rate and increased ovarian autoantibody concentrations.

Although the mechanism by which ovarian autoimmunity occurs is not understood fully, several possibilities have been suggested for mammalian ovaries. Environmental insults, such as noxious chemicals, industrial waste, viruses and other pathogens may invade ovarian tissues (Hill et al., 1990). As a consequence of a depleted population of CD8 T cells during ageing, environmental agents or viral infection may induce interferon (IFN)- $\alpha$ or $-\beta$. 


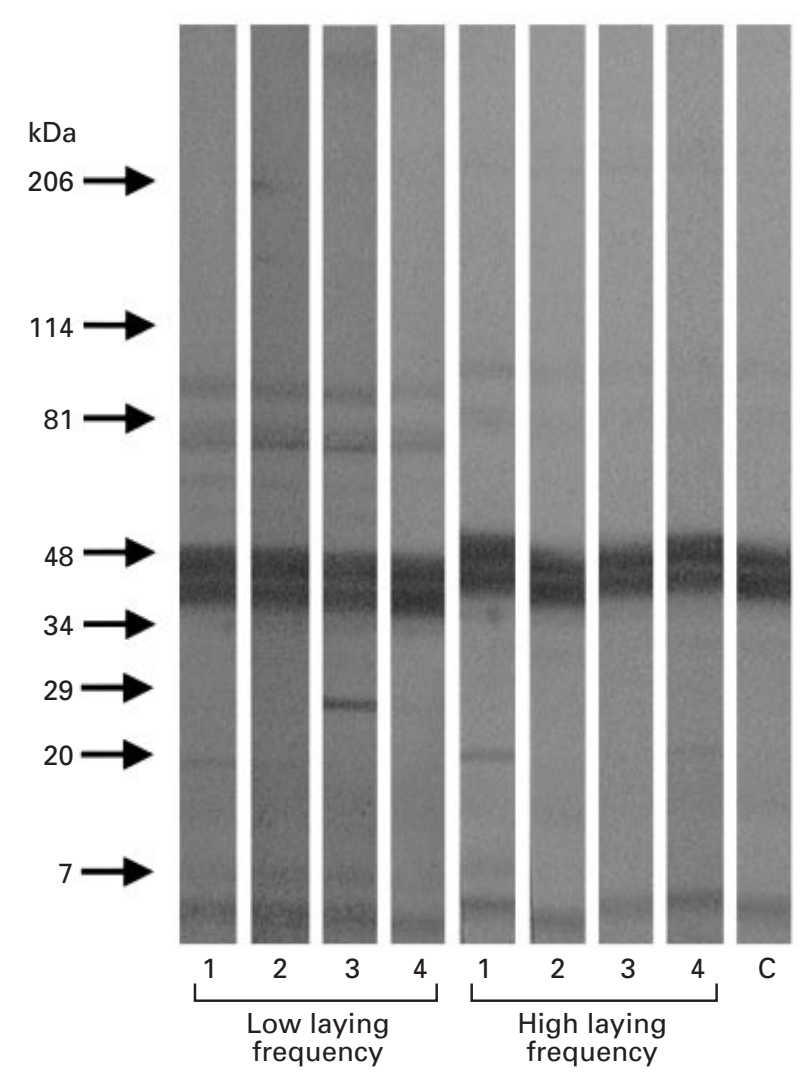

Fig. 5. Western blotting for serum from old laying hens against small white follicle antigens. Low laying frequency: hens aged approximately 670 days with $<50 \%$ egg production (individual hens 1-4). High laying frequency: hens aged approximately 670 days with $>90 \%$ egg production (individual hens $1-4$ ). C: background control in which serum was omitted. Values in the left margin indicate the molecular size of protein bands. Dense bands of approximately 40-48 kDa show endogenous IgG that was contained in the ovarian tissue as they appear in lane C.

These cytokines can activate CD4 T cells to produce IFN- $\gamma$. Increased production of IFN- $\gamma$ may induce abnormal expression of MHC II antigens in ovarian tissues, as well as other organs, triggering the synthesis of autoantibodies in women (Bottazzo et al., 1983; Hill et al., 1990; Coulam and Stern, 1991). Michael (1983) reported that a balanced ratio of CD4:CD8 T cells was essential for normal ovarian function and an increased CD4:CD8 $\mathrm{T}$ cell ratio could stimulate the production of ovarian autoantibodies in mammals. In birds, autoimmunity may occur against the thyroid gland and a possible mechanism of induction has been proposed (Witebsky et al., 1969; Katz et al., 1981). Macrophages can induce inappropriate responses against chicken tissues and may cause localized tissue destruction (Klasing, 1991). For example, activated macrophages are implicated in mediating spontaneous autoimmune thyroiditis in obese chicken lines, possibly due to impaired CD8 T cell activity (Diertert et al., 1987). From the studies of autoimmunity in mammalian ovaries and avian thyroid glands, the common features in induction of autoimmunity are likely to be immunity decline, disruption in MHC II expression to recognize self by macrophages or other antigen presenting cells and imbalance in CD4 and CD8 T cell populations.

Recently, the presence of macrophages (Barua et al., 1998a), MHC II expressing cells (Barua and Yoshimura, 1999a) and T cell subsets (Barua and Yoshimura, 1999b) in hen ovaries have been reported. Although it is not known whether functional disorder of MHC-II occurs in hen ovaries, the populations of MHC-II expressing cells, macrophages and $\mathrm{T}$ cell subsets decreased with ageing, indicating that there is a decrease in immunity during ageing (Barua et al., 1998a; Barua and Yoshimura, 1999a,b). Furthermore, CD4:CD8 ratio was increased in old hens with a greater decrease in CD8 T cell populations than in CD4 $\mathrm{T}$ cell populations (Barua and Yoshimura, 1999b). These findings indicate that the population of immunocompetent cells in hen ovaries is likely to change during ageing in a similar way to autoimmune induction in mammalian ovaries and avian thyroid glands. Therefore, during ageing, hen ovarian autoimmunity may be induced by disordered ovarian immune function, including decreased immunity and possibly self-recognition by MHC-II and abnormal $\mathrm{T}$ cell function.

In conclusion, the results of the present study indicate that anti-ovarian antibodies appear in the circulation of laying hens during ageing. The concentration of antiovarian antibodies was significantly higher in low laying frequency old hens than in high laying frequency old hens, indicating that there is an inverse correlation between the appearance of anti-ovarian antibodies and egg production. It is possible that ovarian autoantibodies are one factor responsible for decreased egg production by old hens.

The authors would like to thank H. Tanimoto, Hiroshima University Experimental Poultry Farm for his excellent care and management of the experimental chickens. This work was supported by Grants-in-Aid for scientific research from the Ministry of Education, Science, Sports and Culture, Japan (No. 12660257) to Y. Yoshimura.

\section{References}

Austin GE, Coulam CB and Ryan RJ (1979) A search for antibodies to luteinizing hormone receptors in premature ovarian failure Mayo Clinical Proceedings 54 394-400

Bahr JM and Palmer SS (1989) The influence of ageing on ovarian function Critical Reviews in Poultry Biology 2 103-110

Barua A and Yoshimura Y (1999a) Immunolocalization of MHC-II+ cells in the ovary of immature, young laying and old laying hens Gallus domesticus. Journal of Reproduction and Fertility 116 385-389

Barua A and Yoshimura Y (1999b) Effects of ageing and sex steroids on the localization of $\mathrm{T}$ cell subsets in the ovary of chicken, Gallus domesticus. General and Comparative Endocrinology 114 28-35

Barua A, Yoshimura Y and Tamura T (1998a) The effects of age and sex steroids on the macrophage population in the ovary of chicken, Gallus domesticus. Journal of Reproduction and Fertility $114253-258$

Barua A, Yoshimura Y and Tamura T (1998b) Effects of ageing and oestrogen on the localization of immunoglobulin-containing cells in the chicken ovary Journal of Reproduction and Fertility 114 11-16 
Benjamini E and Leskowitz S (1991) Autoimmunity. In Immunology - A Short Course pp 315-329. Willy-Liss Inc., New York

Bottazzo GF, Pujol-Borrel R, Hanafusa T and Fieldman R (1983) Role of aberrant HLA-DR expression and antigen presentation in the induction of endocrine autoimmunity Lancet 2 1115-1118

Bradford MM (1976) A rapid and sensitive method for the quantification of microgram quantities of protein utilizing the principle of protein-dye binding Analytical Biochemistry 72 248-254

Cameron IT, O'Shea FC, Rolland JM, Hughes EG, De-Kretser DM and Healy DL (1988) Occult ovarian failure: a syndrome of infertility, regular menses, and elevated follicle-stimulating hormone concentrations Journal of Clinical Endocrinology and Metabolism 67 1190-1194

Chiauzzi V, Ciggorrarga S, Escobar ME, Rivarola MA and Charreau EH (1982) Inhibition of follicle stimulating hormone receptor binding by circulating immunoglobulins Journal of Clinical Endocrinology and Metabolism 54 1221-1228

Coulam CB (1982) Premature gonadal failure Fertility and Sterility 38 645-655

Coulam CB and Stern JJ (1991) Immunology of ovarian failure American Journal of Reproductive Immunology 25 169-174

Dietert RR, Qureshi MA, Gause WC, Trembicki KA and Marsh JA (1987) Detection of a macrophage population in the thyroids of obese strain chickens using monoclonal antibodies Progress in Clinical and Biological Research 238 109-112

Fenichel P, Sosset C, Barbarino-Monnier P, Gobert B, Hieronimus S, Bene MC and Harter M (1997) Prevalence, specificity and significance of ovarian antibodies during spontaneous premature ovarian failure Human Reproduction 12 2623-2628

Hill JA, Welch WR, Faris HM and Anderson DJ (1990) Induction of class II major histocompatibility complex antigen expression in human granulosa cells by interferon gamma: a potential mechanism contributing to autoimmune ovarian failure American Journal of Obstetrics and Gynecology 162 534-540

Irvine WJ, Chan MM, Scarth L, Kolb FO, Hartog M, Bayliss RI and Drury MI (1968) Immunological aspects of premature ovarian failure associated with idiopathic Addison's disease Lancet 26 883-887

Johnson AL (1996) The avian ovarian hierarchy: a balance between follicle differentiation and atresia Poultry and Avian Biology Reviews 7 99-110

Katz DV, Kite JH and Albini B (1981) Immune complexes in tissues of obese strain (OS) chickens Journal of Immunology 126 2296-2301
Kim JG, Moon SY, Chang YS and Lee JY (1995) Autoimmune premature ovarian failure Journal of Obstetrics and Gynecology 21 59-66

Klasing KC (1991) Avian inflammatory response: mediation by macrophages Poultry Science 70 1176-1186

LaBarbera AR, Miller MM, Ober C and Rebar RW (1988) Autoimmune etiology in premature ovarian failure American Journal of Reproductive Immunology and Microbiology 16 115-122

Laemmli UK (1970) Cleavage of structural protein during the assembly of the head of bacteriophage T4 Nature 227 680-685

Luborsky JL, Visintin I, Boyers S, Asari T, Caldwell B and DeCherney A (1990) Ovarian antibodies detected by immobilized antigen immunoassay in patients with premature ovarian failure Journal of Clinical Endocrinology and Metabolism 70 69-75

Michael SD (1983) Interaction of the thymus and the ovary. In Factors Regulating Ovarian Function pp 445-464 Eds GS Greenwald and PF Terrnova. Raven Press, New York

Monacayo R and Monacayo HE (1992) Autoimmunity and the ovary Immunology Today 13 255-258

Richards JS (1980) Maturation of ovarian follicles: action and interaction of pituitary and ovarian hormones on follicular cell differentiation Physiology Review 60 51-89

Ruehsen MM, Blizzard RM, Garcia-Bunuel R and Jones GS (1972) Autoimmunity and ovarian failure American Journal of Obstetrics and Gynecology 112 693-703

Vallotton MB and Forbes AP (1966) Antibodies to cytoplasm of ova Lancet 30 264-265

Waddington D, Perry MM, Gilbert AB and Hardie MA (1985) Follicular growth and atresia in the ovaries of hens (Gallus domesticus) with diminished egg production rates Journal of Reproduction and Fertility 74 399-405

Wheatcroft NJ, Toogood AA, Li TC, Cooke ID and Weetman AP (1994) Detection of antibodies to ovarian antigens in women with premature ovarian failure Clinical and Experimental Immunology 96 122-128

Witebsky E, Kite JH, Wick G and Cole RK (1969) Spontaneous thyroiditis in the obese strain of chickens. 1. Demonstration of circulating autoantibodies Journal of Immunology 103 708-715

Received 15 May 2000.

Accepted 26 July 2000. 